\title{
Birth prevalence of congenital anomalies in the City of Buenos Aires, Argentina, according to socioeconomic level
}

\author{
Ruben Bronberg ${ }^{1,2,3}$ (D) $\cdot$ Boris Groisman ${ }^{2,4} \cdot$ Maria Paz Bidondo ${ }^{2,5} \cdot$ Pablo Barbero $^{2} \cdot$ Rosa Liascovich ${ }^{2,4}$
}

Received: 21 September 2019 / Accepted: 9 December 2019 /Published online: 3 January 2020

(C) Springer-Verlag GmbH Germany, part of Springer Nature 2020

\begin{abstract}
The goal of our study is to describe the prevalence of congenital anomalies (CA) in hospitals of the City of Buenos Aires, Argentina, according to two proxy variables of the socioeconomic level: health subsector, public (PUB) versus private/social security (PRI), and geographical location, northern $(\mathrm{N})$ versus southern $(\mathrm{S})$. The source of data was the National Network of Congenital Anomalies of Argentina (RENAC) (period 2010-2016). From a total of 228,208 births, 4872 newborns with CA were detected (2.14\%). The prevalence in PRI-N, PUB-N, PRI-S, and PUB-S hospitals were 1.59\%, 1.91\%, 2.20\%, and 2.43\%, respectively. Prevalence of neural tube defects, abdominal wall defects, and oral clefts was significantly higher in PUB than in PRI hospitals. Prevalence of critical heart defects was significantly lower in PUB-N and in PRI-S hospitals. Prevalence of anencephaly, encephalocele, hydrocephalus, microcephaly, gastroschisis, cleft lip and palate, ductus arteriosus, and bilateral renal agenesis was higher in PUB hospitals, both $\mathrm{N}$ and $\mathrm{S}$, as well as microphthalmia/anophthalmia and ambiguous genitalia, spina bifida, anotia/microtia, postaxial polydactyly, and diaphragmatic hernia had higher prevalences in PUB-S hospitals. Omphalocele was more frequent in PUB-N hospitals. Results suggest that vulnerable populations in the public and southern subsectors of the city still require a greater support to reinforce resources and strategies that lead to greater equity in access to health.
\end{abstract}

Keywords Birth defects $\cdot$ Buenos Aires City $\cdot$ Socioeconomic status

\section{Introduction}

Congenital anomalies are structural or functional alterations, sporadic or inherited, of prenatal origin, which occur from birth, even when they may be detected later in life. Their determinants are genetic factors, maternal diseases, infections, exposure to medications during pregnancy, and environmental

Ruben Bronberg

rabronberg@intramed.net

1 Ramos Mejía Hospital, Buenos Aires, Argentina

2 National Network of Congenital Anomalies of Argentina (RENAC), National Center of Medical Genetics, National Administration of Health Laboratories and Institutes, National Ministry of Health, Buenos Aires, Argentina

3 Buenos Aires Government Research Committee, Buenos Aires, Argentina

4 National Scientific and Technical Research Council (CONICET), Buenos Aires, Argentina

5 Medicine College, University of Buenos Aires (UBA), Buenos Aires, Argentina pollutants, among others (Stevenson et al. 1993). Around 94\% of newborns with birth defects are born in low- and middleincome countries, placing an additional burden on families, communities, and health systems (Christianson et al. 2006).

In Argentina, infant mortality (IM) was 9.3 per 1000 births in 2017; neonatal mortality (NM) accounted for approximately two thirds of the total IM ( 6.7 per 1000 births). IM decreased by 27\% between 2007 and 2016; however, the reduction was different according to the main causes; infant deaths due to congenital anomalies were reduced by only $8.4 \%$ in that period (Dinamia, Ministry of Health 2018). Congenital anomalies are currently the 2nd cause of IM in Argentina and represent approximately $28 \%$ of total infant deaths (DEIS) 2016).

The City of Buenos Aires is the capital city of Argentina, and it has the highest human development index (0.889) and the lowest percentages of population with unsatisfied basic needs $(7.0 \%)$ and illiteracy $(0.5 \%)$ (Dirección General de Estadísticas y Censos de la Ciudad de Buenos Aires n.d.). The IM and the NM in the City of Buenos Aires were 6.7\%o and $4.8 \%$, respectively in 2017 , values that are among the lowest of the country. In turn, the City of Buenos Aires is the jurisdiction with the lowest percentage reduction of the 
MN in the period 2007-2016 (Dinamia, Ministry of Health 2018). A recent study for the $2010-2015$ period showed a higher specific infant mortality for congenital anomalies in the southern region of the Buenos Aires City (2.9\%o), when compared with the northern region $(2.1 \%$ ) (Bronberg and Dipierri 2019).

The association between congenital anomalies and socioeconomic status has been previously reported (Mage et al. 2019; Baldacci et al. 2018; Yu et al. 2014; Vrijheid et al. 2000). In Argentina, a study identified a significant association between low socioeconomic status and an increased risk of cleft lip with or without cleft palate and ventricular septal defect (Pawluk et al. 2014).

The contribution of congenital anomalies in the IM and NM supports analyzing groups by geographic region and subsectors of health care to assess the effect of socioeconomic status. The objective of this study is to describe birth prevalence of total congenital anomalies and by specific categories, and compare these prevalences among hospitals, according to the health subsector, public (PUB) versus private/social security (PRI), and their geographical location, northern region $(\mathrm{N})$ versus southern region $(\mathrm{S})$ of the city.

\section{Materials and methods}

The design of the study was ecological. We investigated the relationship between the prevalence of congenital anomalies at birth and the socioeconomic level, in the City of Buenos Aires. Two proxy variables of the socioeconomic level were considered, the health subsector (PUB versus PRI), and the geographic location of birthing hospitals (northern region versus southern region of the Buenos Aires City, using Rivadavia Avenue as an artificial boundary).

The source of data was the National Network of Congenital Anomalies of Argentina (RENAC), the national surveillance system for congenital anomalies (Groisman et al. 2013). RENAC is a hospital-based system which includes approximately 150 hospitals in the 24 jurisdictions of the country, with coverage of around $40 \%$ of total births and $60 \%$ in the public subsector.

In RENAC, the calculation of prevalence is based on the number of cases with congenital anomalies detected in each participating hospital (numerator) and the total number of births of the same hospitals (denominator). The case definition includes all newborns and stillbirths weighing $500 \mathrm{~g}$ or more with major structural anomalies, external or internal, identified from delivery to hospital discharge, and detected by physical examination or complementary studies, surgeries, or autopsies. Cases with minor or functional congenital anomalies are excluded. The detection and description of the anomalies is carried out by the local staff of the hospitals; the clinical review (coding and classification of cases), by two geneticists of the coordination (MPB and PB). Coding is done using the International Classification of Diseases, Tenth Revision (ICD10), adapted by the Royal College of Pediatrics and Child Health. The clinical classification of cases includes three mutually exclusive categories: isolated anomalies, multiple anomalies, and syndromes (Rasmussen et al. 2003). RENAC does not include routine information about risk factors or the socioeconomic status of families.

For the present study, the 22 hospitals belonging to RENAC in the City of Buenos Aires were included; 13 were PUB (6 from the north and 7 from the south), which reported in the period October 2010-December 2016; and 9 were PRI ( 7 from the north and 2 from the south), which reported between January 2013 and December 2016 (Fig. 1). The coverage of RENAC in the City of Buenos Aires public subsector is close to $100 \%$, because all the maternity hospitals of this subsector are included; in the private subsector, coverage is $35 \%$.

Four groups of cases with congenital anomalies born in city hospitals were defined: cases born in PRI-N hospitals, cases born in PUB-N hospitals, cases born in PRI-S hospitals, and cases born in PUB-S hospitals. In these four groups, the prevalence of congenital anomalies was calculated for the total cases, for 6 categories of congenital anomalies grouped, and for 34 specific anomalies with more than 25 cases selected according to their impact on morbidity and mortality. The prevalence was calculated according to the Poisson distribution, with a $95 \%$ confidence interval. In these four groups, we also calculated the percentages of mothers with advanced age $(\geq$ 35 years), young mothers ( $\leq 19$ years), multiparous mothers ( $\geq 4$ children), preterm $(\leq 37$ weeks $)$, low weight $(\leq 2500 \mathrm{~g})$, prenatal detection, and cases that died before hospital discharge.

To compare the prevalence of total anomalies and specific selected anomalies among the four groups of hospitals, a chisquare test was used, with a significance level of 0.05 . For each specific selected anomaly, a "Z" score was obtained considering the prevalence of PRI-N hospitals as a reference (expected value), and the other three groups as comparison values: PUB-N hospitals (Z1), PRI-S hospitals (Z2), and PUB-S hospitals (Z3) (observed values) $[Z=$ (observed value of expected value)/square root (expected value)]. A $p$ value of 0.0005 was established using Bonferroni's correction for multiple comparisons.

To graphically show the differences in prevalence among the four groups for specific selected anomalies, the Equiplot chart, developed to visualize health inequalities (International Center for Health Equity), was used. The statistical software Stata version 13 was used.

\section{Results}

From a total of 228,208 births examined in the hospitals that reported to RENAC in the City of Buenos Aires, 98,728 (43\%) 
Fig. 1 Health subsector and geographic location of the birthing hospitals included in RENAC, City of Buenos Aires, Argentina. PRI, private/social security; PUB, public; N, northern; $\mathrm{S}$, southern

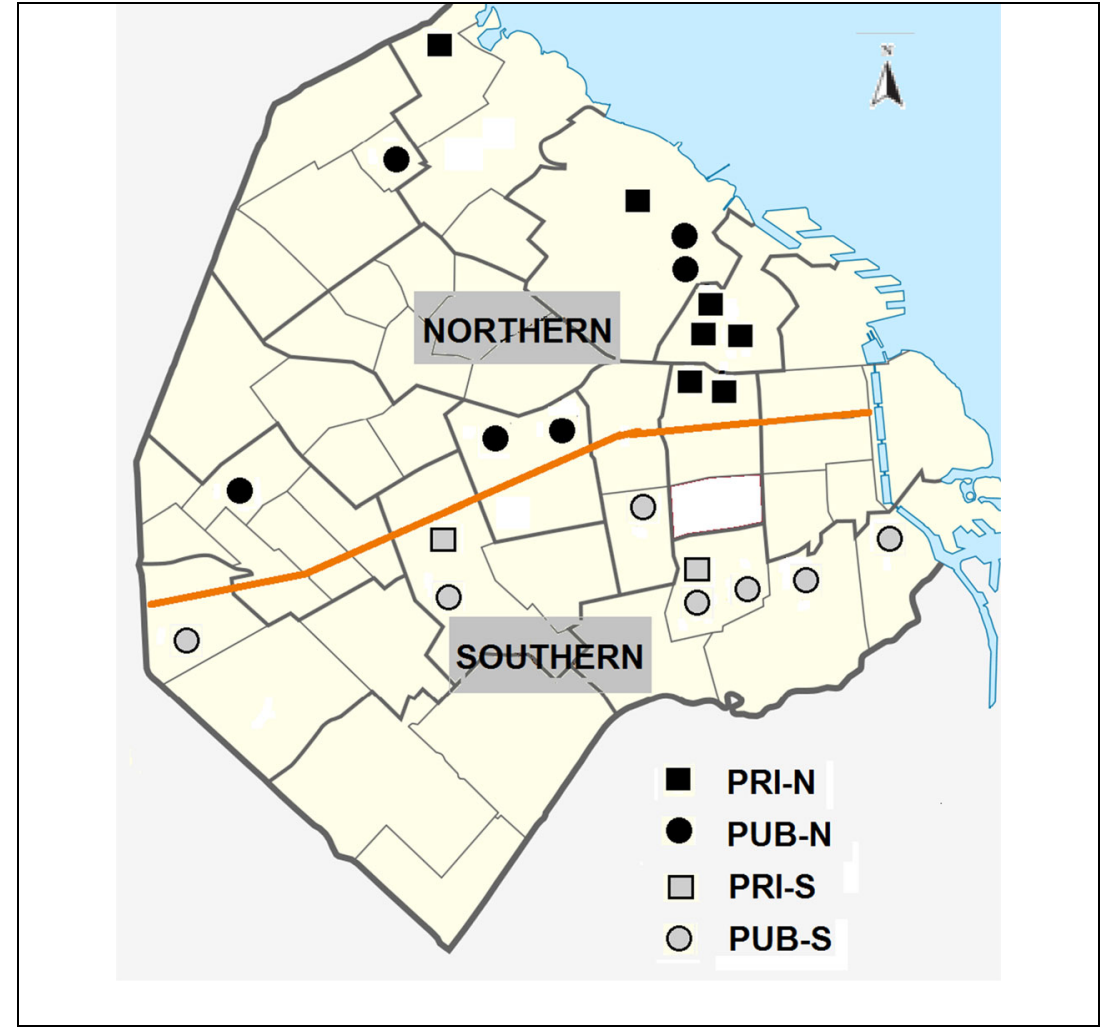

were born in hospitals of the north, and 129,480 (57\%) in hospitals of the south; in turn, 174,090 (76\%) births occurred in public hospitals, and 54,118 (24\%) in private/SS hospitals.

A total of 4872 newborns with major congenital anomalies (cases) were detected, with a global prevalence of $2.14 \%$ (95\% CI 2.08-2.20). The lowest prevalence was observed in PRI-N hospitals $1.59 \%$ (95\% CI 1.48-1.71), followed by PUB-N hospitals $1.91 \%$ (95\% CI 1.80-2.04), then by PRI-S hospitals 2.20 (95\% CI $1.87-2.56$ ), and finally by PUB-S hospitals 2.43 (95\% CI 2.35-2.52) (Table 1).
The distribution of the cases according to their clinical presentation and other associated variables is presented in Table 2. Among the four groups of birth hospitals, there are no differences in the clinical presentation, except that the frequency of cases with multiple congenital anomalies is significantly higher in public northern hospitals. In the four groups, the proportion of isolated cases is the highest, followed by syndromic cases and multiple congenital anomalies.

No statistically significant differences were observed among cases of the four hospital groups in relation to mortality
Table 1 Prevalence of congenital anomalies, according to the health subsector and geographic location of the birth hospitals. RENAC, Buenos Aires City

\begin{tabular}{clll}
\hline Birth hospitals & Examined births $(N)$ & Cases with congenital anomalies $(N)$ & Prevalence (95\% CI) \\
\hline Northern & 98,728 & 1738 & $1.76(1.68-1.85)$ \\
PRI $^{1}$ & 46,707 & 743 & $1.59(1.48-1.71)$ \\
PUB $^{2}$ & 52,021 & 995 & $1.91(1.80-2.04)$ \\
Southern & 129,480 & 3134 & $2.42(2.34-2.51)$ \\
PRI $^{3}$ & 7411 & 163 & $2.20(1.87-2.56)$ \\
PUB $^{4}$ & 122,069 & 2971 & $2.43(2.35-2.52)$ \\
Total & 228,208 & 4872 & $2.14(2.08-2.20)$ \\
\hline
\end{tabular}

$P R I$ private/social security, $P U B$ public

${ }^{1}$ Hospitals: Alemán, Anchorena, Clínicas, F. Hospitalaria, Otamendi, Suizo, Trinidad Palermo

${ }^{2}$ Hospitals: Álvarez, Durand, Fernández, Pirovano, Rivadavia, Vélez

${ }^{3}$ Hospitals: Churruca, Santa Isabel

${ }^{4}$ Hospitals: Argerich, Garrahan, Penna, Piñeyro, Ramos Mejía, Santojani, Sardá 
Table 2 Clinical presentation, maternal and newborn variables of cases with congenital anomalies, according to health subsector and geographic location of the birthing hospitals. RENAC, City of Buenos Aires, Argentina

\begin{tabular}{|c|c|c|c|c|c|c|c|c|c|}
\hline \multirow[t]{2}{*}{ Birth hospitals } & & \multicolumn{3}{|l|}{ Northern } & \multicolumn{4}{|l|}{ Southern } & \multirow[t]{2}{*}{ Total, $N(\%)$} \\
\hline & & PRI, $N(\%)$ & PUB, $N(\%)$ & $\mathrm{Z1}$ & PRI, $N(\%)$ & $\mathrm{Z} 2$ & PUB, $N(\%)$ & $\mathrm{Z3}$ & \\
\hline \multirow[t]{3}{*}{ Clinical presentation } & Syndromic $(\%)$ & $141(19.6)$ & $173(18.8)$ & 1.0 & $30(19.9)$ & -0.4 & 433 (15.9) & -2.8 & $777(17.2)$ \\
\hline & Isolated $(\%)$ & $499(69.3)$ & $594(64.5)$ & -2.5 & $102(67.5)$ & -1.5 & $1.971(72.3)$ & -0.3 & $3.166(70.1)$ \\
\hline & Multiple (\%) & $80(11.1)$ & $154(16.7)$ & $3.9^{*}$ & $19(12.6)$ & 0.7 & $323(11.8)$ & 0.1 & $576(12.7)$ \\
\hline \multirow[t]{3}{*}{ Maternal variables } & Maternal age $\geq 35$ years & $335(45.1)$ & $228(22.9)$ & $-9.0^{*}$ & $42(25.8)$ & $-7.8^{*}$ & $552(18.6)$ & $-10.8^{*}$ & $1157(23.7)$ \\
\hline & Maternal age $\leq 19$ years & $15(2.0)$ & $144(14.5)$ & $23.9^{*}$ & $10(6.1)$ & $7.9^{*}$ & $517(17.4)$ & $29.5^{*}$ & $686(16.4)$ \\
\hline & Multiparity $(\geq 4)$ & $74(10.0)$ & $122(12.3)$ & 2.0 & $29(17.8)$ & $6.8^{*}$ & $460(15.5)$ & $4.8^{*}$ & $685(14.1)$ \\
\hline \multirow[t]{4}{*}{ Newborn variables } & $\operatorname{Preterm}(\leq 37 \mathrm{~s})$ & $325(43.7)$ & 427 (42.9) & -0.3 & $66(40.5)$ & -1.3 & $1153(38.8)$ & -2.0 & $1971(40.5)$ \\
\hline & Low weight $(\leq 2500)$ & 237 (31.9) & $301(30.3)$ & -0.8 & $42(25.8)$ & -2.9 & $875(29.5)$ & -1.2 & 1455 (29.9) \\
\hline & Prenatal diagnosis & $280(37.7)$ & $276(27.7)$ & $-4.4^{*}$ & $61(37.4)$ & -0.1 & $825(27.8)$ & $-4.4^{*}$ & $1442(29.6)$ \\
\hline & Neonatal death & $107(14.4)$ & $176(17.7)$ & 2.4 & $26(16.0)$ & 1.1 & $526(17.7)$ & 2.4 & $835(17.1)$ \\
\hline
\end{tabular}

$P R I$ private/social security, $P U B$ public

$\mathrm{Z}$ values: reference, PRI northern hospitals

*Statistically significant. Statistical significance was established using the Bonferroni adjustment for multiple comparisons, at $Z= \pm 2.9$

at hospital discharge, the percentage of preterm births, and low weight. Advanced maternal age $(\geq 35)$ was significantly more frequent in PRI-N hospitals, while young maternal age $(\leq 19)$ was significantly higher in PUB hospitals, both northern and southern. Southern hospitals, both PRI and PUB, had a higher proportion of multiparous mothers ( $\geq 4$ children). Prenatal diagnosis was significantly higher in PRI hospitals, both northern and southern (Table 2).

Prevalence of neural tube defects and abdominal wall defects was significantly higher in PUB hospitals than in PRI hospitals. Prevalence of critical heart defects was significantly lower in PUB-N hospitals and in PRI-S hospitals. Oral clefts had a significantly higher prevalence in PUB-N hospitals, and even higher in southern, whether PUB or PRI. The chromosomal anomalies and talipes did not show statistically significant differences (Table 3).

Prevalence of anencephaly, encephalocele, hydrocephalus, microcephaly, gastroschisis, and bilateral renal agenesis was significantly higher in PUB hospitals, both the northern and southern. Anencephaly and hydrocephalus also had a high prevalence in PRI-S hospitals, as well as microphthalmia/ anophthalmia and ambiguous genitalia, spina bifida, anotia/ microtia, postaxial polydactyly, and diaphragmatic hernia had a significantly higher prevalence in PUB-S hospitals. Cleft lip and palate and patent ductus arteriosus were significantly more prevalent in southern hospitals, both PUB and PRI. Omphalocele was significantly more frequent in PUB-N hospitals (Table 4, Fig. 2).

The prevalence of congenital anomalies in each group and the distance between groups shown in Equiplot (Fig. 2) allow to compare the absolute inequality in health, observed in the public and southern sectors of the city.

\section{Discussion}

In Argentina, the health sector is comprised of three subsectors. The public subsector, which is financed through taxes, is available free of charge to the entire population and serves approximately $46 \%$ of people. The social security system is funded by mandatory contributions from employers and registered workers and covers about $44 \%$ of the population. The private insurance system is for profit, is paid directly by the insured, and serves $10 \%$ of the population, with higher income (Bidondo et al. 2015). The three systems have little coordination among them, which results in overlapping, inefficiency, and high health expenditure (about $6.61 \%$ of the gross domestic product). In the City of Buenos Aires, the three health subsystems (public, social security, and private) differ regarding the population covered, the provided services, and the funding sources; however, these subsectors have coordination issues (Arce 2012).

The city is crossed from east to west by an important street on Rivadavia Avenue that functions as an artificial boundary between the northern and southern areas of the city. On one side and the other of the Rivadavia Avenue, which originates from the Plaza Mayor, the different neighborhoods that make up the city were formed since the eighteenth century.

There is a residential segregation closely related to socioeconomic groups, with the middle and upper classes located close to the northern part of the city. As a result of this residential segregation, the socioeconomic level of the population tends to decrease from east to west and from north to south, in agreement with the Buenos Aires urban development and population settlement pattern. 
Educational differences regarding geographical areas could also be observed. The southern area had the highest levels of school adolescent absenteeism and desertion and the lowest levels of education among adults. Socioeconomic characterization of the city with a set of housing indicators (type of housing, sewer system connection), social composition of the group (overcrowding, poverty line, family income, educational level), and educational facilities (type of school, distance to school, etc.) also revealed poverty towards the south of the city (Groisman and Suárez 2006; Bronberg et al. 2009).

In this study, the prevalence of congenital anomalies was analyzed according to the health subsector and the geographic location of the birthing hospital, including both resident and non-resident mothers in the City of Buenos Aires. Prevalence of congenital anomalies showed a differential behavior according to the health subsystem and the region of the newborn hospital. The lowest prevalence was observed in PRI-N hospitals, while the highest in PUB-S hospitals.

The only congenital anomaly that presented a higher prevalence in PRI-N hospitals was critical heart defects (19.5 per 1000), a finding that may be due to better detection capacity in these centers. Undiagnosed cases of severe heart disease have an impact on infant morbidity and mortality. The fact that PRI$\mathrm{N}$ has better detection generates inequality and probably a higher mortality due to severe congenital heart defects in facilities that are not part of PRI-N.

The percentage of prenatal detection of critical heart defects was 55\% in PRI-N hospitals, similar to the 50\% reported in an international study including 12 countries from Europe, North and South America, and Asia (Bakker et al. 2019). Prenatal detection of critical heart defects in PUB hospitals was lower, $33 \%$ in the north and $40 \%$ in the south. In the south, one maternity hospital (Sardá Maternity) contributed with a high proportion of cases. This maternity hospital is a center for the referral of high-risk pregnancies from different provinces, and it shows a relatively high prevalence of critical heart defects (14.7 per 1000).

Neural tube defects, as a category, are significantly more prevalent in PUB hospitals in both regions. The same was observed when anencephaly and encephalocele were analyzed separately. Spina bifida also had a higher prevalence in PUB hospitals, but without statistical significance in the north. The prevalence of anencephaly in PRI-N hospitals is strikingly low $(0.6 \times 1000)$, which could be due to a higher proportion of prenatal ultrasound detection and subsequent elective termination of pregnancy, coupled with a better nutritional status and more adequate periconceptional folic acid intake in a population of higher socioeconomic status. Then, in spite of the universal fortification of wheat with folic acid, there would be worse nutrition and probably less vitamin supplementation in the public subsector population. In this sense, the National Survey of Nutrition and Health revealed that poor folate intake is higher in households with unsatisfied basic needs (NBI) 


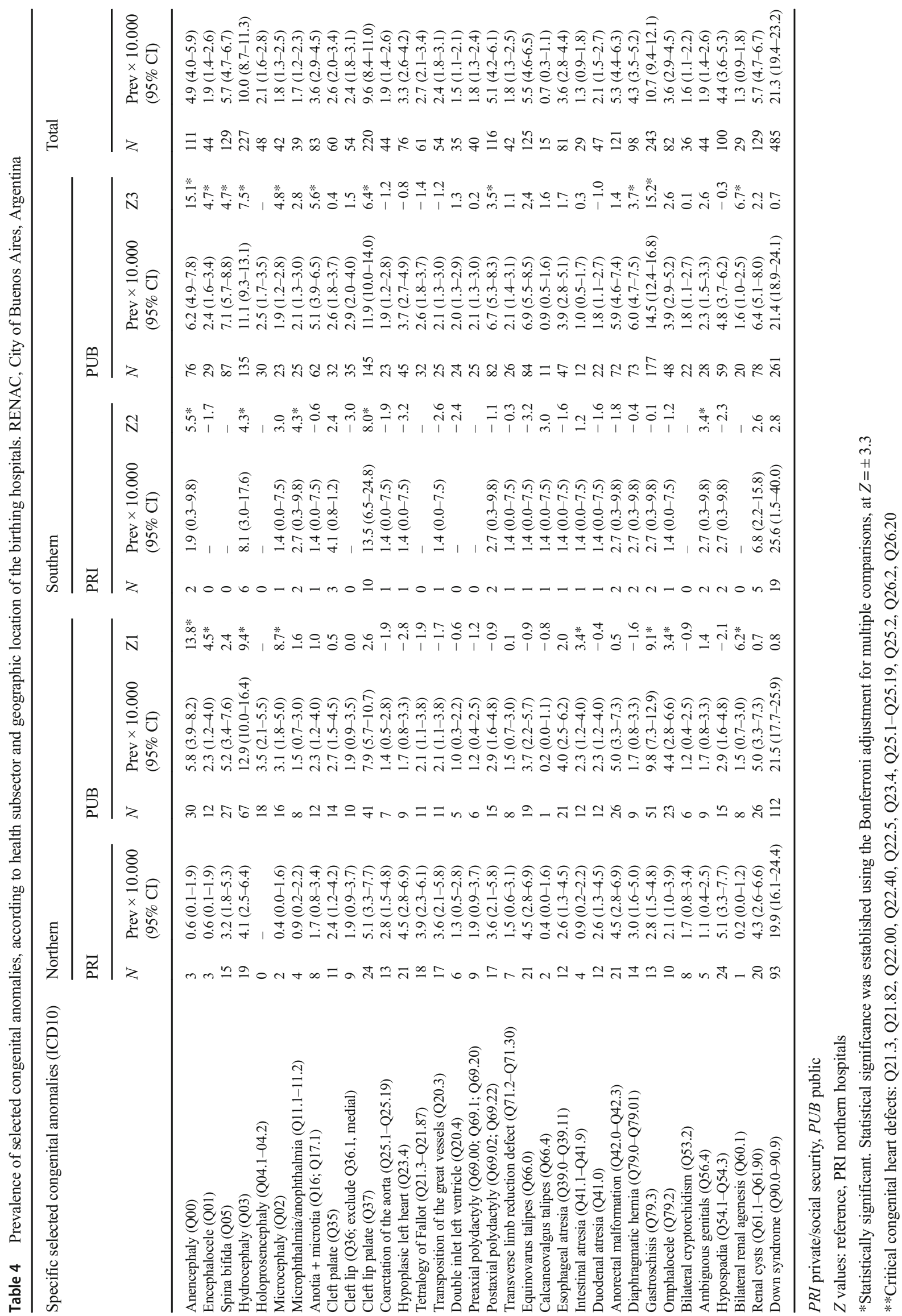




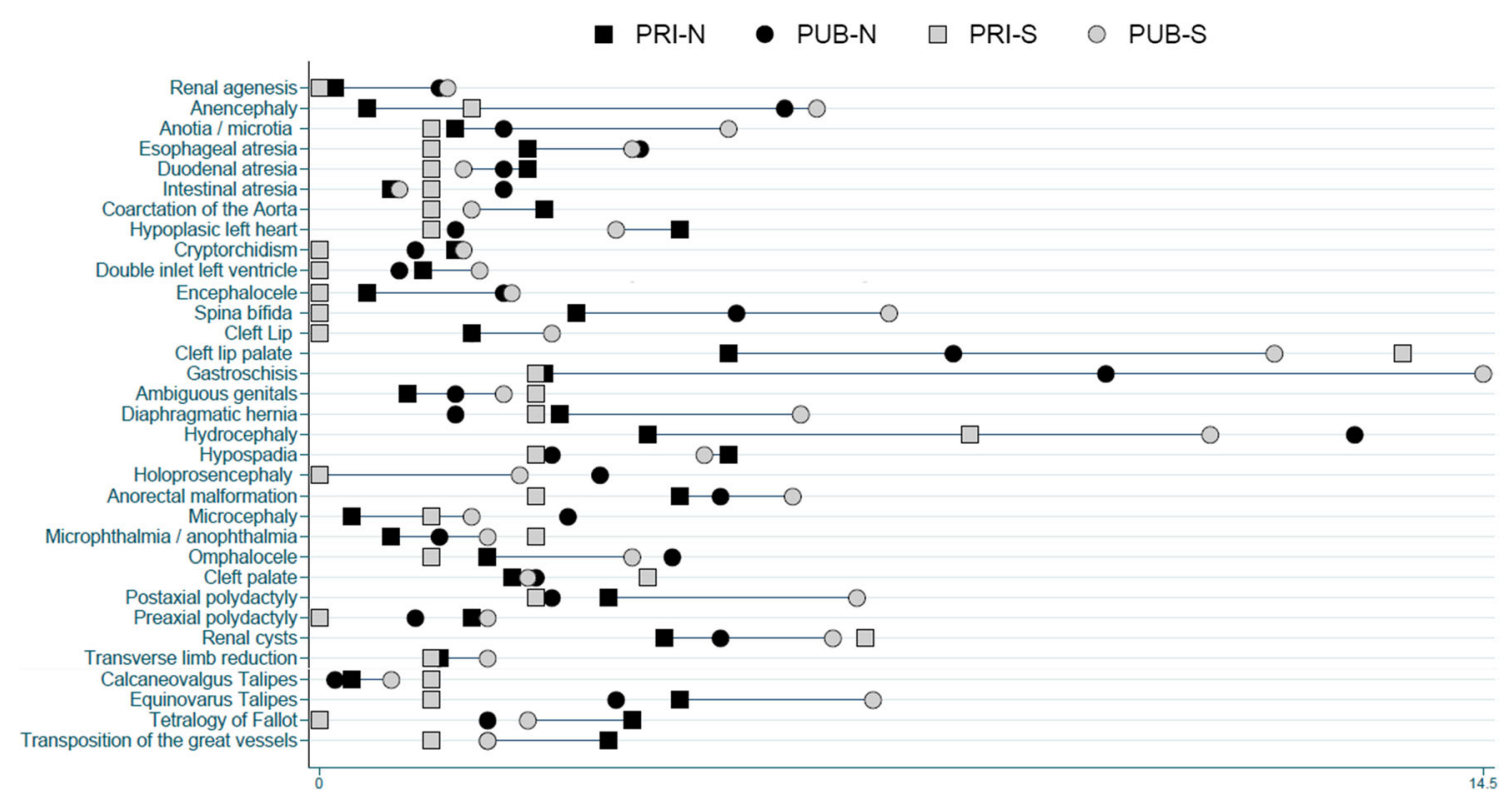

Fig. 2 Equiplot graph of the prevalence (\%) of selected congenital anomalies, according to health subsector and geographic location of the birthing hospitals in RENAC. PRI, private/social security; PUB, public; N, northern; S, southern

than in households without NBI (ENNyS, National Survey on Nutrition and Health 2007). In a study based on 314 pregnant women who attended the Sardá Maternity between 2000 and 2002 for prenatal control before the 16th week of gestation, near half of them did not reach minimal levels of serum folate (Perego et al. 2005). In our study, the majority ( $82 \%$ ) of neural tube defects were isolated cases, therefore sensitive to fortification. As with anencephaly, renal agenesis (a single case) and holoprosencephaly (no cases observed), in PRI-N and PRI-S hospitals, could be due to better prenatal ultrasound detection and subsequent termination of affected pregnancies in a population of higher socioeconomic status.

The prevalence of gastroschisis is higher in PUB hospitals, especially in the south. There is evidence that gastroschisis is associated with young maternal age $(<20$ years) (Goldbaum et al. 1990; Castilla et al. 2008; Baer et al. 2015) and probably with recurrent genitourinary infections in young women (Feldkamp et al. 2019). In our study, maternal age under 20 was $14.5 \%$ and $17.4 \%$ in PUB-N and PUB-S hospitals, respectively, and $2.0 \%$ and $6.1 \%$ in PRI-N and PRI-S hospitals, respectively. These data are consistent with publications by the National Health Statistics of the City of Buenos Aires, which show that maternal age $<20$ years is $11.7 \%$ and $14.4 \%$ in PUB-N and PUB-S hospitals, and $1.4 \%$ and $4.3 \%$ in PRI-N and PRI-S hospitals, respectively (DEIS) 2016). A study related to genitourinary infections in public hospitals of the south of the City of Buenos Aires showed positive percentages of VDRL above $4 \%$, consistent with the higher incidence rates of syphilis in pregnant women from the south of the city. Two public hospitals in the northern region had the lowest rates, with less than half of syphilis cases than the average in the city (Health Situation Análisis de Situación de la Salud de Buenos Aires 2016).

Although advanced maternal age ( $\geq 35$ years) was much prevalent in PRI-N hospitals, the frequency of Down syndrome did not show significant differences among the 4 groups. We interpret that this would be due to better prenatal detection and subsequent termination of affected pregnancies in the population of higher socioeconomic status. Previous studies suggest that inequality in access to prenatal diagnosis and subsequent termination of pregnancy, due to socioeconomic differences, has created disparities in the prevalence of Down syndrome (Khoshnood et al. 2006).

Oral clefts were more prevalent in PUB-N hospitals, and even more in southern hospitals, whether PUB or PRI hospitals. Specifically, cleft lip and palate were more frequent in PUB-N hospitals (although without statistical significance) and significantly more prevalent in southern hospitals, both PUB and PRI. Oral clefts in Argentina have been associated with low socioeconomic status, mainly due to poor prenatal care, low educational level, lifestyle factors, acute maternal diseases, and native ancestors (Pawluk et al. 2018). Other studies also detected a high frequency cluster of oral clefts in the NOA region (Poletta et al. 2007, Groisman et al. 2017). Many families that attend PUB hospitals of the City of Buenos Aires, especially those in the south, have native ancestors and come from that region of the country. In recent studies, parental consanguinity was associated with the appearance of non-syndromic oral clefts (Silva et al. 2019; Saeed et al. 2019). In a study that evaluated the genetic structure of the City of Buenos Aires by the method of isonymy, a greater inbreeding and a 
smaller variety of surnames were observed in the districts located in the south of the city (Bronberg et al. 2009).

The relatively high prevalence of microphthalmia/ anophthalmia and ambiguous genitalia in PRI-S hospitals could be due to random variations, since there are few cases with those congenital anomalies. Diaphragmatic hernia has a significantly higher prevalence in PUB-S hospitals, but $29 \%$ of these cases come from the Garrahan Hospital, which has a special prenatal referral program for postnatal surgical treatment.

According to a recent study (Golubicki et al. 2018), $49 \%$ of neonatal mortality of the Buenos Aires City was due to congenital anomalies, which represented the leading cause in 2016. From the total neonatal deaths due to congenital anomalies, $43 \%$ of cases had prenatal diagnosis, $55 \%$ were treated in non-public establishments, and $39 \%$ had congenital heart defects.

In developing countries, maternal and child health coverage remains highly inequitable and access to services is influenced by factors such as income, level of education, and place of residence (Adegbosin et al. 2019). The factors that determine the prevalence of congenital anomalies are multiple. Low socioeconomic level is a risk factor of congenital anomalies through different mechanisms: young maternal age, malnutrition, and greater exposure to teratogenic agents. Additionally, low socioeconomic level is associated to lower detection of congenital anomalies, due to the lack of prenatal diagnosis or postnatal detection in lower complexity of health effectors.

There are different programs in Argentina for the primary prevention of congenital anomalies (supplementation of wheat flour with folic acid, immunization for congenital rubella) and secondary-tertiary prevention (neonatal screening of inborn errors of metabolism, national congenital heart disease program, early detection of congenital hearing loss). However, the results of our study suggest that vulnerable populations in the public and southern subsectors of the city still require greater efforts by the authorities and health effectors to strengthen resources and design strategies that lead to more equity in access to health.

Funding information RENAC was supported by the National Center for Genetic Medicine (CNGM, ANLIS C. Malbrán), the National Ministry of Health (NMH) of Argentina, Grants: Abraam Sonis 2016-2017, the National Agency for Science and Technology, and the National Ministry of Science and Technology of Argentina.

Data availability statement The data that support the findings of this study are available from the corresponding author upon reasonable request.

\section{Compliance with ethical standards}

Ethical statement In the present study, the data of the RENAC public health surveillance system was used. The data are anonymized. Therefore, the study is within the specific answers in Resolution
1480/2011 of the Ministry of National Health in Argentina (Guide for Research with Human Beings), which states that "the sources of health systems, official health programs or public health surveillance in which is not no possibility of individual identification are not subject to evaluation by an Ethics Committee."

\section{References}

Adegbosin AE, Zhou H, Wang S, Stantic B, Sun J (2019) Systematic review and meta-analysis of the association between dimensions of inequality and a selection of indicators of Reproductive, Maternal, Newborn and Child Health (RMNCH). J Glob Health 9(1):010429

Análisis de Situación de la Salud de Buenos Aires (2016). Available at https://www.buenosaires.gob.ar/sites/gcaba/files/asis_caba_2016 dic17 vf 1.pdf. Accessed 2019-09-01

Arce HE (2012) Organización y financiamiento del sistema de salud en la Argentina. Revista Medicina (Buenos Aires) 72:414-418

Baer RJ, Chambers CD, Jones KL, Shew SB, MacKenzie TC, Shaw GM, Jelliffe-Pawlowski LL (2015) Maternal factors associated with the occurrence of gastroschisis. Am J Med Genet A 167(7):1534-1541

Bakker MK, Bergman JEH, Krikov S, Amar E, Cocchi G, Cragan J, de Walle HEK, Gatt M, Groisman B, Liu S, Nembhard WN, Pierini A, Rissmann A, Chidambarathanu S, Sipek A Jr, Szabova E, Tagliabue G, Tucker D, Mastroiacovo P, Botto LD (2019) Prenatal diagnosis and prevalence of critical congenital heart defects: an international retrospective cohort study. BMJ Open 9(7):e028139

Baldacci S, Gorini F, Santoro M, Pierini A, Minichilli F, Bianchi F (2018) Environmental and individual exposure and the risk of congenital anomalies: a review of recent epidemiological evidence. Epidemiol Prev 42(3-4 Suppl 1):1-34

Bidondo MP, Groisman B, Barbero P, Liascovich R (2015) Public health approach to birth defects: the Argentine experience. J Community Genet 6(2):147-156

Bronberg RA, Dipierri JE (2019) Infant mortality due to congenital malformations in the Autonomous City of Buenos Aires (19982015): spatial, temporal analysis and relation to the socioeconomic status. Arch Argent Pediatr 117(3):171-178

Bronberg RA, Dipierri JE, Alfaro EL, Barrai I, Rodríguez-Larralde A, Castilla EE, Colonna V, Rodríguez-Arroyo G, Bailliet G (2009) Isonymy structure of Buenos Aires city. Hum Biol 81(4):447-461

Castilla EE, Mastroiacovo P, Orioli IM (2008) Gastroschisis: international epidemiology and public health perspectives. Am J Med Genet C: Semin Med Genet 148C(3):162-179

Christianson A, Howson C, Modell B (2006) Global report on birth defects. The hidden toll of dying and disabled children. March of Dimes Birth Defects Foundation White Plains, New York. Available at https://www.marchofdimes.org/global-report-on-birth-defectsthe-hidden-toll-of-dying-and-disabled-children-full-report.pdf

Dinamia (2018) Regionalización perinatal en la Argentina: barreras, experiencias y avances en el proceso de regionalización perinatal. Ministerio de Salud de la Nación. Dirección Nacional de Maternidad, Infancia y Adolescencia. Available at http://www. msal.gob.ar/images/stories/bes/graficos/0000000176cnt-n02regionalizacion.pdf. Accessed 2019-09-01

Dirección de Estadísticas e Información de Salud (DEIS) (2016) Ministerio de Salud y Desarrollo Social de la Nación. Estadísticas Vitales, Información Básica Año. Available at http://www.deis.msal. gov.ar/

Dirección General de Estadísticas y Censos de la Ciudad de Buenos Aires (n.d.) La mortalidad infantil de la Ciudad en el período 2015/2017. Available at https://www.estadisticaciudad.gob.ar/eyc/wp-content/ uploads/2018/05/ir_2018_1270.pdf. Accessed 2019-09-01 
Encuesta nacional de nutrición y salud (ENNyS) (2007). Available at http://www.msal.gob.ar/images/stories/bes/graficos/ 0000000257cnt-a08-ennys-documento-de-resultados-2007.pdf. Accessed 2019-09-01

Feldkamp ML, Arnold KE, Krikov S, Reefhuis J, Almli LM, Moore CA, Botto LD (2019) Risk of gastroschisis with maternal genitourinary infections: the US National birth defects prevention study 19972011. BMJ Open 9(3):e026297

Goldbaum G, Daling J, Milham S (1990) Risk factors for gastroschisis. Teratology 42(4):397-403

Golubicki A, Sabbag D, Vinocur E, Salgado P. (2018). Mortalidad Neonatal en la Ciudad de Buenos Aires 2016. Análisis y caracterización de las muertes ocurridas en la Ciudad en el ámbito público y no público de salud

Groisman F, Suárez A (2006) Segregación residencial en la Ciudad de Buenos Aires. Revista Población de Buenos Aires, Dirección General de Estadística y Censos Buenos Aires, Argentina 3(4):2737

Groisman B, Bidondo MP, Barbero P, Liascovich R (2013) RENAC: National Registry of Congenital Anomalies of Argentina. Arch Argent Pediatr 111:484-494

Groisman B, Gili J, Giménez L, Poletta F, Bidondo MP, Barbero P, Liascovich R, López-Camelo J (2017) Geographic clusters of congenital anomalies in Argentina. J Community Genet 8(1):1-7

Khoshnood B, De Vigan C, Vodovar V, Bréart G, Goffinet F, Blondel B (2006) Advances in medical technology and creation of disparities: the case of Down syndrome. Am J Public Health 96(12):2139-2144

Mage DT, Maria Donner E, Holmes L Jr (2019) Risk differences in disease-specific infant mortality between black and white US children, 1968-2015: an epidemiologic investigation. J Racial Ethn Health Disparities 6(1):86-93

Pawluk MS, Campaña H, Gili JA, Comas B, Giménez LG, Villalba MI, Scala SC, Poletta FA, López Camelo JS (2014) Adverse social determinants and risk for congenital anomalies. Arch Argent Pediatr 112(3):215-223
Pawluk MS, Campaña H, Rittler M, Poletta FA, Cosentino VR, Gili JA, Gimenez LG, López Camelo JS (2018) Individual deprivation, regional deprivation, and risk for oral clefts in Argentina. Rev Panam Salud Publica 41:e110

Perego MC, Briozzo G, Durante C (2005) Estudio bioquímiconutricional en la gestación temprana en la Maternidad Sardá de Buenos Aires. Acta Bioquim Clin Latinoam 39(2):187-196

Poletta FA, Castilla EE, Orioli IM, Lopez-Camelo JS (2007) Regional analysis on the occurrence of oral clefts in South America. Am J Med Genet A 143A(24):3216-3227

Rasmussen SA, Olney RS, Holmes LB, Lin AE, Keppler-Noreuil KM, Moore CA; National Birth Defects Prevention Study (2003) Guidelines for case classification for the National Birth Defects Prevention Study. Birth Defects Res A Clin Mol Teratol 67(3): 193-201

Saeed OB, Moore MG, Zawahrah H, Tayem M, Kavoosi T, van Aalst JA (2019) The influence of consanguinity on familial clefting among Palestinians. Cleft Palate Craniofac J

Silva CM, Pereira MCM, Queiroz TB, Neves LTD (2019) Can parental consanguinity be a risk factor for the occurrence of nonsyndromic oral cleft? Early Hum Dev 135:23-26

Stevenson RE, Hall JH, Goodman RM (1993) Human malformation and related anomalies Oxford monographs on medical genetics n. 27. Oxford University Press, New York

Vrijheid M, Dolk H, Stone D, Abramsky L, Alberman E, Scott JE (2000) Socioeconomic inequalities in risk of congenital anomaly. Arch Dis Child 82(5):349-352

Yu D, Feng Y, Yang L, Da M, Fan C, Wang S, Mo X (2014) Maternal socioeconomic status and the risk of congenital heart defects in offspring: a meta-analysis of 33 studies. PLoS One 9(10):e111056

Publisher's note Springer Nature remains neutral with regard to jurisdictional claims in published maps and institutional affiliations. 